\title{
THREE-DIMENSIONAL MULTI-PIPE ROUTE OPTIMIZATION BASED ON GENETIC ALGORITHMS
}

\author{
Huanlong Wang ${ }^{1}$,Cuilian Zhao ${ }^{1}$,Weichun Yan $^{2}$,Xiaowei Feng ${ }^{1}$ \\ ${ }^{1}$ College of Mechanicals Engineering and Automation, Shanghai University, Shanghai \\ 200072, China;Email:whllenny-2000@163.com; ${ }^{2}$ Shanghai Turbine CO.,LTD. Shanghai \\ 200240, China
}

\begin{abstract}
To optimize the design of three-dimensional multi-pipe, multi-constraint and multi-objective path planning, an approach based on Genetic Algorithms (GA) is presented in this paper, which includes definition of genes to deal with pipe routes, definition and application of fitness functions, and definition of punishing function set by constraints. An example and good simulation results are also presented to show the validity of this approach.
\end{abstract}

Key words: route optimization; GA; Encapsulated Oil Pipes (EOP).

\section{INTRODUCTION}

In the system of ships, aeroengines and turbines, which has complicated pipe system, the route optimization is always a research hotspot. The route optimization not only releases burden of manual design, but also enhances efficiency of design and reduces cost of design and manufacturing. Though having function of general pipe design, some commercial CAD softwares, such as UG, SOLIDWORKS and CATIA etc., don't have function of the route optimization for some special industries. And researchers mainly focused on the route optimization of two-dimensional pipes or threedimensional and single one, but relatively less in the multi-pipe, multiconstraint and multi-objective route optimization previously. Taking the route optimization of the $\mathrm{EOP}^{1}$ of turbine as an example, this paper will present an approach for the "three-multi" optimization problem, which may be useful to other route optimization.

Please use the following format when citing this chapter:

Wang, Huanlong, Zhao, Cuilian, Yan, Weichun, Feng, Xiaowei, 2006, in International Federation for Information Processing (IFIP), Volume 207, Knowledge Enterprise: Intelligent Strategies In Product Design, Manufacturing, and Management, eds. K. Wang, Kovacs G., Wozny M., Fang M., (Boston: Springer), pp. 177-183. 
A lot of works have been done in the route optimization of threedimensional pipes, and relative study is developing from the simple twodimensional route optimization in the early days to the three-dimensional multi-pipe, multi-constraints and multi-objective route optimization now.

In 1976, sprout method adopted "Depth-First Search" to optimize route ${ }^{2}$, which needed more information. In 1985, Dijstra adopted weighted graph $(\mathrm{G}=(\mathrm{V}, \mathrm{E}, \mathrm{W})$ where: $\mathrm{V}$ : a group of connecting points; $\mathrm{E}$ : cyclometer of connecting points; $\mathrm{W}$; weighted value to describe pipe space and solve the route optimization problem ${ }^{3}$.And then some developed methods, such as adjoining nodes algorithm, the shortest route rapid algorithm and Dijkstra algorithm with evaluating function ${ }^{4}$, were proposed, which were only to solve the single pipe problem, instead of considering the multi-pipe one just like the kind of route optimization problems of EOP of turbine. In 2003, Fan jiang proposed the path planning in the pipe system based on coevolution, which was only suitable to the two-dimensional pipe system ${ }^{5}$.

Now the main algorithms of path planning are as follows:

- Lee Routing Algorithm ${ }^{6}$ : it is a kind of maze algorithm, which is one of the oldest Lee Routing Algorithms. M.Dorigo proposed Ant Colony Algorithm ${ }^{7}$ based on maze algorithm.

- Method based on AI and KBE: the process of pipe design is a kind of sequent one, which agglomerates designers' intelligence and experience. So the pipe planning and expert system can be developed to enhance the design efficiency by the technology of $\mathrm{AI}$ and $\mathrm{KBE}$.

- Path planning based on Simulated Annealing (SA)

- Path planning based on GA: it is quite useful to the route optimization, and can be applied to solve the multi-pipe, multi-constraint route optimization problem.

\section{ALGORITHM OF THE ROUTE OPTIMIZATION UNDER KNOWN CONDITON}

\subsection{Condition setting}

Supposed that the relative position of entrance and exit section of each pipe has been known. Data are transited to Excel as an initial data frame from an outer system by data transition (Fig.1). And then the route can be optimized by GA. Followed the flow chart (Fig. 2). 

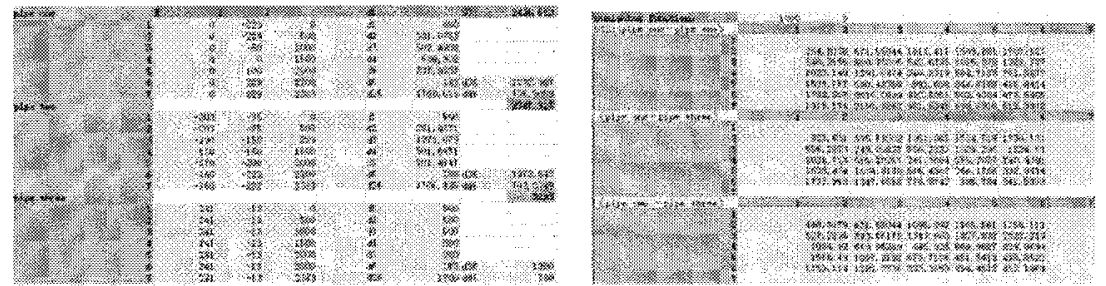

Figure 1. Data frame

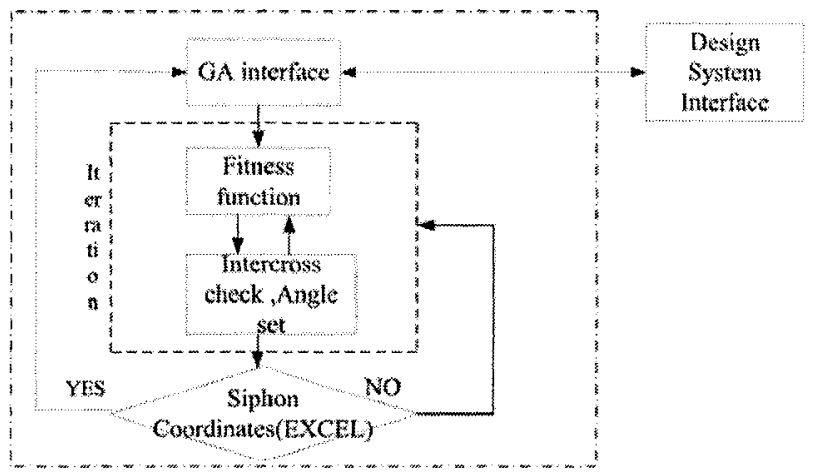

Figure 2. Flow chart

\subsection{Coding method}

Encoding is a chief aspect of designing and applying GA. Considering the three-dimensional and big data, the coordinate parameters are encoded by floating number, number of bend pipes by integer, the whole variable by coupling multi-parameter. And the code length of each individual "p" is changed with the variable " $\mathrm{N}$ " (the number of bend pipes). It is as follows:

$$
\begin{aligned}
& x_{1,3} \ldots x_{1, m 2} x_{1, m 1} x_{2,3} \ldots x_{2, m 2} x_{2, m 1} x_{3,3} \ldots \ldots x_{3, m 2} x_{3, m 1} y_{1,3} \ldots \ldots . y_{1, m 2} y_{1, m 1} y_{23} \ldots \ldots . y_{2, m 2} y_{2, m 1} y_{3,3} \ldots \ldots . y_{3, m 2} y_{3, m 1} \\
& z_{1,2} \cdots . . z_{1, m 2} z_{1, m-1} z_{1, m} z_{2,2} \cdots . . z_{2 m 2} z_{2, m 1} z_{2, m} z_{3,2} \cdots . . z_{3, m 2} z_{3, m 1} z_{3, m} N_{1} N_{2} N_{3}
\end{aligned}
$$

Where:

$x_{i, j} y_{i, j} z_{i, j}$ : the coordinates of each pipe; $i=1$ :oil pipe one; $i=2$ :oil pipe two; $i=3$ :oil pipe three; $j: 1 \sim \mathrm{m}$; and $z_{i, j+1} \geq z_{i, j}$;

$N_{k}$ : the number of each bend pipe; $k=1:$ oil pipe one; $k=2$ : oil pipe two; $k=3$ : oil pipe three; $m$ : the number of strait pipe; $m=\mathrm{N}+1$; 


\subsection{Selection of fitness function}

The selection of fitness function is very important. For the optimization problem with constraints, it can be performance index, or be transformed from the performance index. This paper is about the shortest path, and constraint is that pipes can't be intersected, and bend pipe angle can't be over $60^{\circ}$. Although GA is the algorithm that deals with the maximum problem., the minimum problem with constraints can be transformed from the maximum problem with the punishing function.

According to pressure loss of fluid in the pipe, the shortest length of pipes and the least number of bend pipes are taken as performance index to form the fitness function $F_{i}$.(Each pipe has the same fitness function).

$$
F_{i}=w_{1} \times\left(1+\frac{S_{i}}{\sum_{j=1}^{m} d_{j}}\right)+w_{2} \times\left(\frac{N_{\max }-N_{i}}{N_{\max }-N_{\min }}\right)+R_{p}
$$

Where:

$i$ :suffix, its meaning is the same to the upper one;

$S_{i}$ :the straight distance between the exit and the entrance section of each pipe;

$f_{i}$ : the objective function of each pipe; $F_{i}:$ the fitness function of each pipe; $N_{i}$ : the number of bend pipes of each pipe;

$w_{1}$ : the weight value of pipe length in the fitness function; $w_{2}$ : the weight value of the number of bend pipes in the fitness function

$d_{i}$ :the length of the single straight pipe; $N_{\min }$ : the mini number of bend pipes; $N_{\max }$ : the max number of bend pipes;

$R_{p}:$ the punishing function, which is defined in case of the intersection between pipes and the bend pipe angle.

\subsection{Selection of the punishing function $R_{p}$}

It is a basic principle for the multiple pipes to avoid intersection and the bigger bend pipe angle. Hence, the intersection points must be deleted in order to the route optimization. And the bend pipe angle also needs restricting to reduce the searching space. For every pipe, the punishing 
function is added to the fitness function to reduce the fitness to delete the bad points when pipes intersect between each other and the bend pipe angle goes beyond the set one. Formula is as follows:

$$
\sqrt{\left(x_{i j}-x_{k g}\right)^{2}+\left(y_{i j}-y_{k g}\right)^{2}+\left(z_{i j}-z_{k g}\right)^{2}}>R_{i}+R_{k}
$$

The bend pipe angle is limited between $0^{\circ}$ and $60^{\circ}$, so the formula is as follows:

$$
-1 \leq \frac{d_{i,(j-1, j)}^{2}+d_{i,(j, j+1)}^{2}-d_{i,(j-1, j+1)}^{2}}{2 \square d_{i,(j-1, j)}\left[d_{i,(j, j+1)}\right.} \leq-0.5
$$

Where:

$$
\begin{aligned}
& d_{i,(j-1, j)}=\sqrt{\left(x_{i, j}-x_{i, j-1}\right)^{2}+\left(y_{i, j}-y_{i, j-1}\right)^{2}+\left(z_{i, j}-z_{i, j-1}\right)^{2}} \\
& d_{i,(j, j+1)}=\sqrt{\left(x_{i, j+1}-x_{i, j}\right)^{2}+\left(y_{i, j+1}-y_{i, j}\right)^{2}+\left(z_{j+1}-z_{j}\right)^{2}} \\
& d_{i,(j-1, j+1)}=\sqrt{\left(x_{i, j+1}-x_{i, j-1}\right)^{2}+\left(y_{i, j+1}-y_{i, j-1}\right)^{2}+\left(z_{i, j+1}-z_{i, j-1}\right)^{2}}
\end{aligned}
$$

$\mathrm{i}, \mathrm{k}: 1 \leq i, k \leq 3$, and $i \neq k$, the symbol of pipe, its meaning is the same to the upper ones; $R_{1}$ : radius of oil pipe one; $R_{2}$ : radius of oil pipe two; $R_{3}$ : radius of oil pipe three ;j, $\mathrm{g}: 1 \leq j, g \leq m$, symbol of the bend pipe coordinates . rules:

For the punishing function, formula is as follows according to the upper

$$
R_{p}=\left\{\begin{array}{l}
0 \\
1000
\end{array} \text { (if interference }: 0 ; \text { otherwise: } 1000\right)
$$

\section{TRIAL ANALYSIS}

The trial analysis of this algorithm is applied to one part of the EOP system, According to the design experience, the max number of the bend pipes is five. The pipe coordinates are as follows: 
Table 1 . The coordinates of entrance and exit

\begin{tabular}{|l|l|l|l|l|l|l|l|}
\hline & $\begin{array}{l}\text { Entrance } \\
\mathrm{X}\end{array}$ & $\mathrm{Y}$ & $\mathrm{Z}$ & Exit X & $\mathrm{Y}$ & $\mathrm{Z}$ & $\begin{array}{l}\text { Diameter } \\
\varnothing\end{array}$ \\
\hline $\begin{array}{l}\text { Sucker for } \\
\text { bearing }\end{array}$ & -229.0 & 0.0 & 0.0 & 0.0 & 229.0 & 2383.0 & 219.0 \\
\hline $\begin{array}{l}\text { Sucker for } \\
\text { primary oil } \\
\text { pump }\end{array}$ & -75.0 & 203.0 & 0.0 & -160.0 & -222.0 & 2383.0 & 168.0 \\
\hline $\begin{array}{l}\text { Cream pipe for } \\
\text { primary oil pipe }\end{array}$ & -13.0 & -241.0 & 0.0 & 241.0 & -13.0 & 2383.0 & 168.0 \\
\hline
\end{tabular}

Set: population size $\mathrm{M}=100$, cross rate $\mathrm{Pc}=0.9$, mutation rate $\mathrm{Pm}=0.01$, generation gap $\mathrm{G}=0.98$, the weight value of length of the pipe $w_{1}=0.3$, the weight value of the number of the bend pipe $w_{2}=0.7$, the setting is as follows:
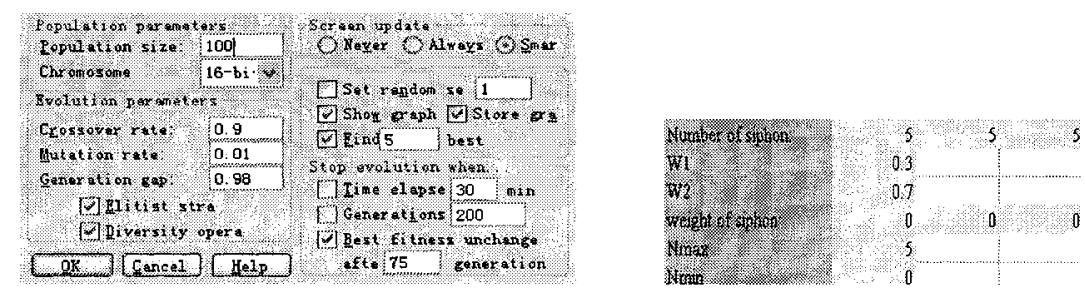

Figure 3. Parameter and weight value setting

Results are as follows after optimization.

Table 2. Optimization results

\begin{tabular}{|c|c|c|c|c|}
\hline & $\mathrm{X}$ & $\bar{Y}$ & $\bar{Z}$ & Number of siphon \\
\hline \multirow[t]{2}{*}{ Sucker for bearing: } & -229.00 & 0.00 & 812.00 & \multirow[t]{2}{*}{2} \\
\hline & 0.00 & 229.00 & 1533.00 & \\
\hline \multirow{5}{*}{$\begin{array}{l}\text { Sucker for primary } \\
\text { oil pump: }\end{array}$} & -75.00 & 203.00 & 299.00 & \multirow[t]{5}{*}{4} \\
\hline & 63.00 & 122.06 & 521.20 & \\
\hline & 128.12 & 84.00 & 1138.74 & \\
\hline & -82.88 & -140.09 & 1434.14 & \\
\hline & -160.00 & -222.00 & 1629.00 & \\
\hline \multirow{6}{*}{$\begin{array}{l}\text { Cream pipe for } \\
\text { primary oil } \\
\text { Pump: }\end{array}$} & -13.00 & -241.00 & 1021.24 & \multirow[t]{6}{*}{5} \\
\hline & 36.33 & -196.72 & 1196.34 & \\
\hline & 130.32 & -183.48 & 1332.80 & \\
\hline & 180.55 & -116.79 & 1481.65 & \\
\hline & 218.57 & -33.19 & 1620.50 & \\
\hline & 241.00 & -13.00 & 1733.00 & \\
\hline
\end{tabular}

The 3D modeling is as follows: 

Algorithms
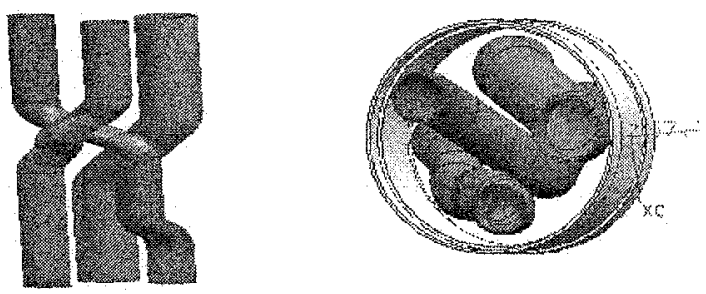

Figure 4.3D modeling

\section{CONCLUSION}

Faced to the multi-pipe, multi-constraint and multi-objective optimization problem, a method based on GA is presented to deal with the pipe route planning. One part of the EOP system is also optimized and its result is quite satisfied. However, some further study is needed as following:

- The weight value is only set by the design experience, which may be thoughtless.

- There is only one part of the EOP system optimized, and the optimization of whole system needs improving.

\section{REFERENCES}

1. Wang Fufang, The quality control and check of the encapsulated oil pipes of large turbines, Machinist (heat process), 3:62-63 (2002).

2. Van $\mathrm{C}$ and Koopmans $J \mathrm{~J} \mathrm{G}$. The optimum routing of pipes in a ship's engine room, Proceedings, Computer Applications in the Automation of Shipyard Operations and Ship Design II, ICCCS 76, 333-341(1976).

3. Funaoka $\mathrm{K}$ and Wumeda $\mathrm{H}$. new integrated ship design system MATES. Proceedings, Computer Applications in the Automation of Shipyard Operations and Ship Design IV, ICCCS 82, 257-268(1982).

4. Qing Li, Dingli Song and Shuangjiang Zhang. Two improved optimum path planning algorithms. Journal of University of Science and Technology Beijing,27(3),367-370(2005).

5. Jiang Fan, Mei Ma and Xiaoguang Yang. Path planning in pipe system based on coevloution. Journal of Aerospace Power. 19(5),593-597(2004).

6. Lee C Y. An algorithm for path connections and its applications. Electronic Computres.(9),346-364(1961).

7. Xiaobing $\mathrm{Hu}$ and Xiyue Huang. Application of ant colony algorithm to maze problem. Computer Emulation, 114-116(1983).

8. Wenxun Xing and Jinxing Xie. The modern optimization algorithms,(Tsinghua Press, Beingiing,1999),pp.90-96. 